Supplement of

\title{
Measurement report: Strong light absorption induced by aged biomass burning black carbon over the southeastern Tibetan Plateau in pre-monsoon season
}

\section{Tianyi Tan et al.}

Correspondence to: Min Hu (minhu@ pku.edu.cn)

The copyright of individual parts of the supplement might differ from the article licence. 

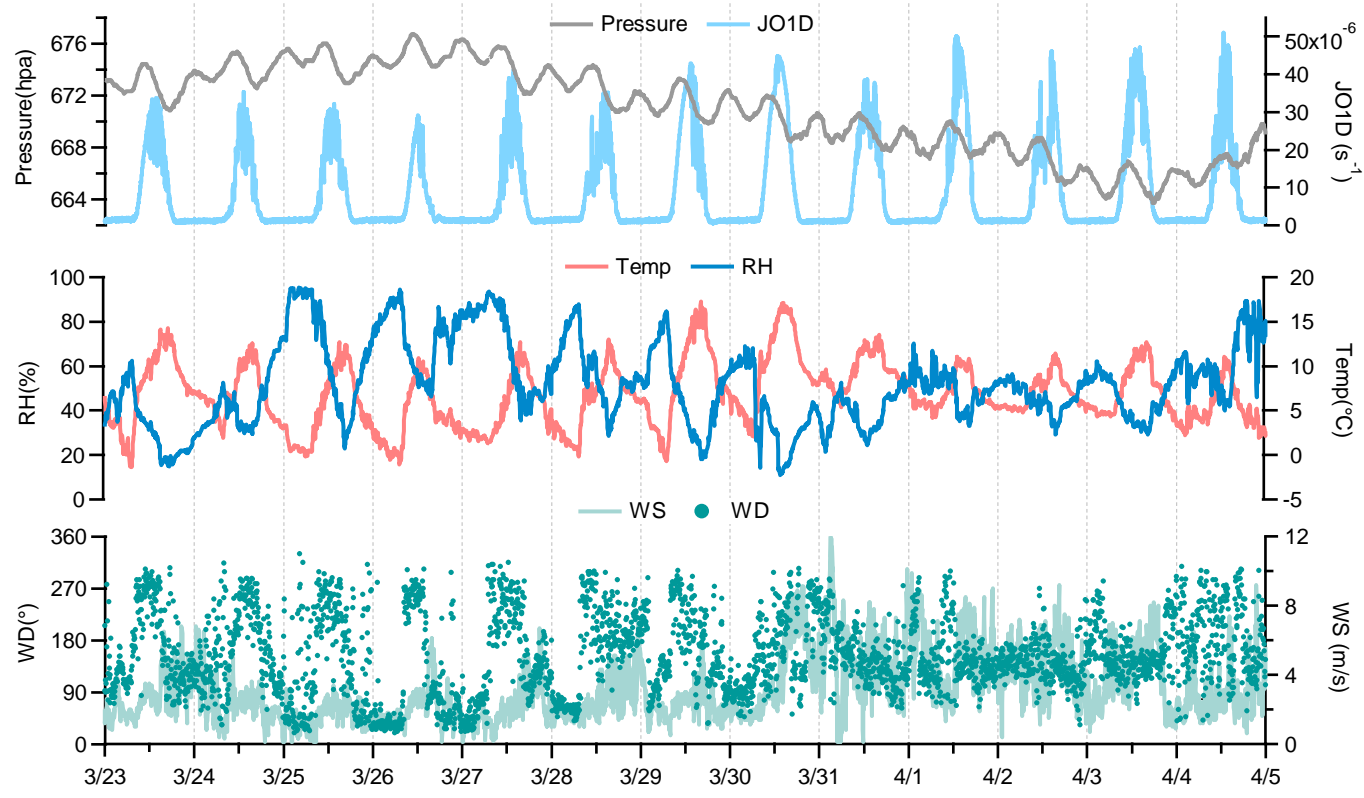

Figure S1. Meteorological conditions during the campaign.

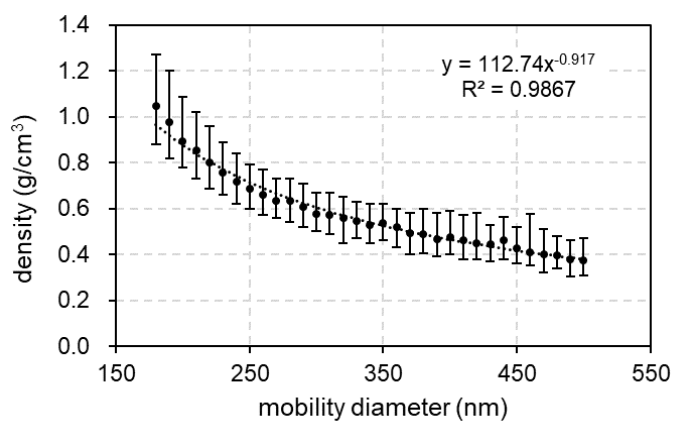

Figure S2. Size-dependently effective density of the BC core for thinly-coated BC particles.

(a) Thinly-coated BC

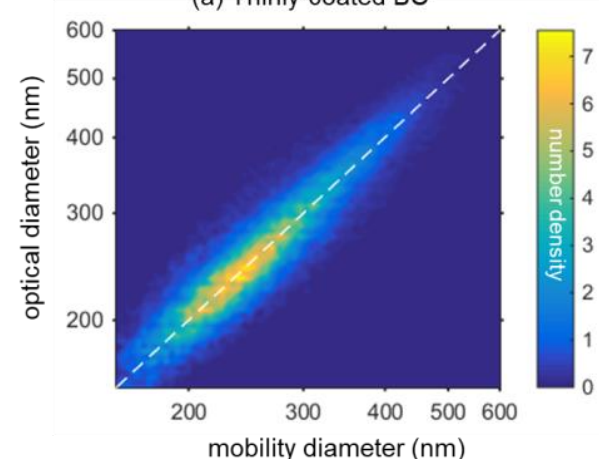

(b) Thickly-coated BC

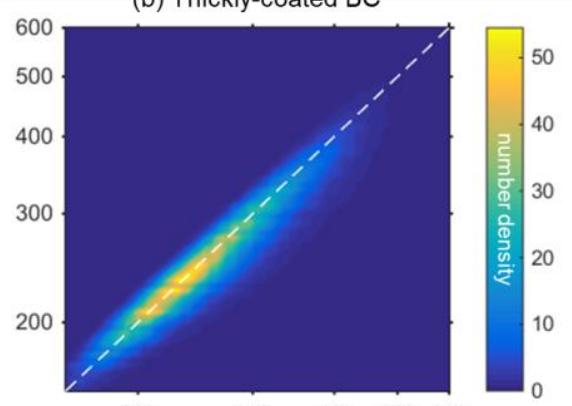

$\begin{array}{llll}200 & 300 & 400 \quad 500600\end{array}$ mobility diameter $(\mathrm{nm})$ 
Figure S3. Comparison between optical diameter and mobility diameter for (a) thinly-coated BC and (b) thickly-coated BC.

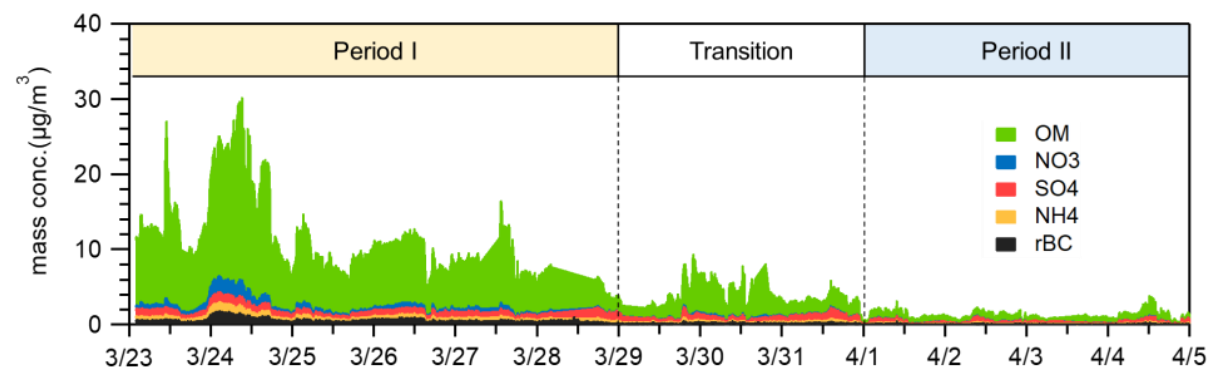

Figure S4. Time series of the aerosol mass concentrations of different chemical species.
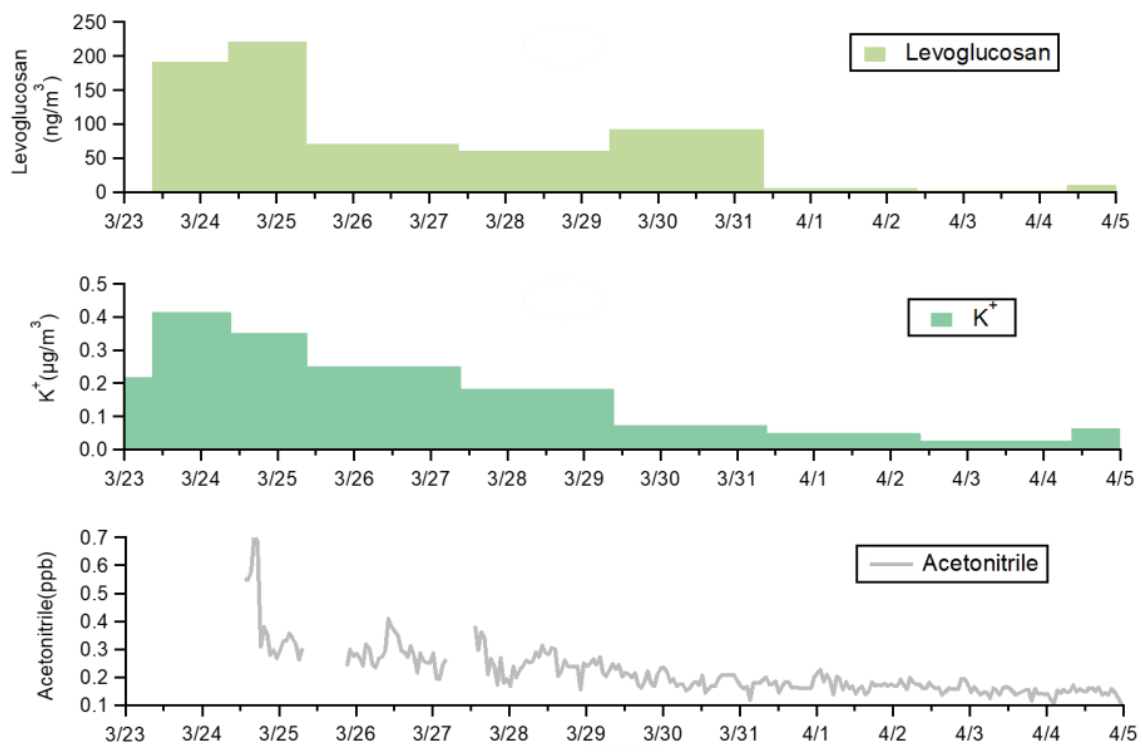

10 Figure S5. Temporal variation of biomass burning tracers during the observation. 

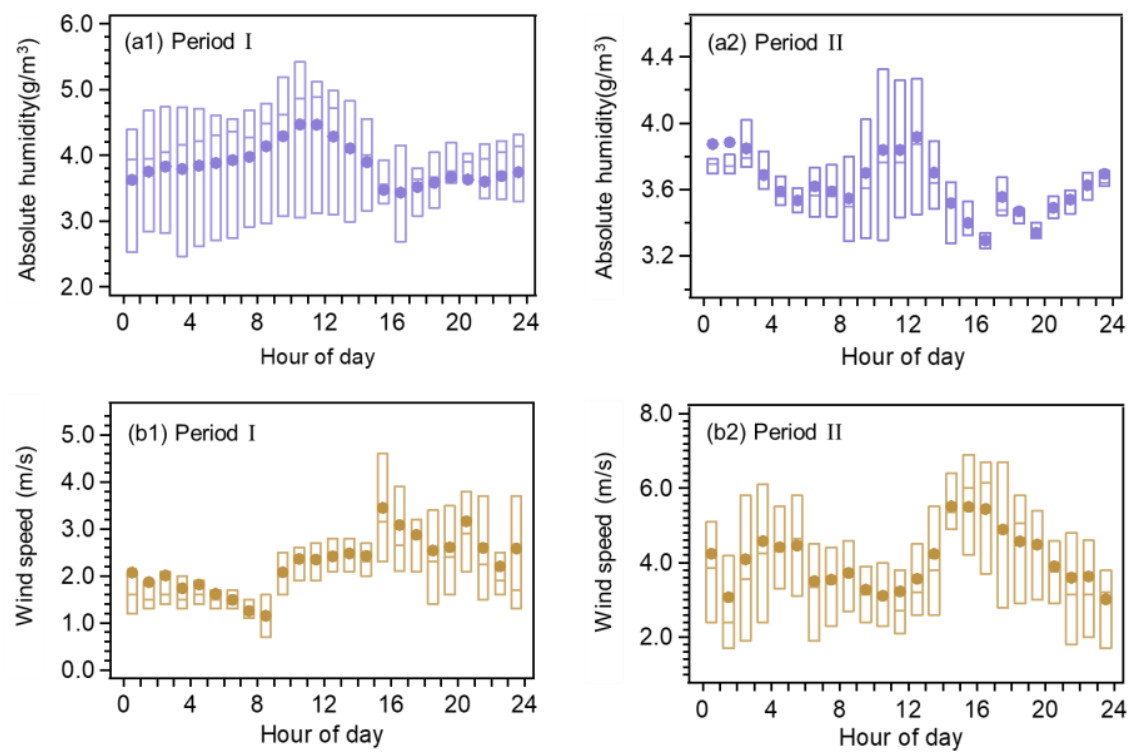

Figure S6. Diurnal variation of absolute humidity (water vapor concentration) and wind speed during Period I and Period II. The solid dots are the mean values. The rectangles cover the data from $25 \%$ to $75 \%$ quantile. The short lines in the middle of the rectangles represent the 15 median values. 